\title{
ANÁLISE DAS BARREIRAS QUE DIFICULTAM A TRANSFORMAÇÃO DO AGRICULTOR FAMILIAR EM EMPREENDEDOR RURAL NO CONTEXTO BRASILEIRO
}

\section{RESUMO}

Apesar da relevância da agricultura familiar, até meados da década de 90, os agricultores brasileiros tinham pouco acesso ao crédito e as políticas públicas existentes muitas vezes não atendiam aos anseios desta população. Em 1996, o governo brasileiro criou o PRONAF - Programa Nacional da Agricultura Familiar, que apesar de inúmeras qualidades, enfrenta desafios relacionados a aspectos sócio-culturais e características psicossociais dos agricultores, que nem sempre conseguem incorporar os comportamentos necessários para serem empreendedores num setor que cada vez mais demanda por inovação e desenvolvimento. Este é o principal objetivo deste trabalho: relacionar a questão do empreendedorismo rural e da agricultura familiar à questão da inovação e do desenvolvimento a partir da análise das barreiras enfrentadas pelo agricultor familiar (AF) que dificultam ou impedem sua transformação em empreendedor rural (ER). Para o estudo destes dois grupos, fizemos entrevistas em profundidade e aplicamos um questionário estruturado a agricultores indicados por uma cooperativa de crédito rural do Sul do Brasil. A análise evidenciou que as barreiras para o empreendedorismo rural estavam associadas à ausência de liderança e capacidade de assumir riscos; e enfatizou a importância da família, das redes sociais e da educação formal no desenvolvimento do AF. Concluímos que os AF não podem ser considerados como potenciais empreendedores schumpeterianos típicos, mas, alguns pontos são importantes para a implementação de políticas públicas: uma abordagem contingencial; direcionamento de recursos para perfis mais empreendedores; favorecer as avaliações objetivas e subjetivas dos resultados da alocação de recursos, desenvolver incubadoras de negócios, formação e educação gerencial.

Palavras-chave: Empreendedorismo Rural; Comportamento Empreendedor, Inovação, Agricultura Familiar.

\section{ANALYSIS OF BARRIERS THAT AFFECT THE TRANSFORMATION OF FAMILY FARMER INTO A RURAL ENTREPRENEUR IN BRAZILIAN CONTEXT}

\begin{abstract}
Despite importance of family agriculture, until the mid 90's, the Brazilian farmers had little or no access to credit and the existing public policies often do not meet the needs of this population. In 1996, the Brazilian government created the PRONAF - Program of Familiar Agriculture, first rural credit program designed exclusively for family farmers (FF) that despite numerous qualities, is facing challenges related to socio-cultural and psychosocial characteristics of farmers who do not always can incorporate the behaviors needed to be rural entrepreneurs (RE) in an industry that increasingly demand for innovation and development. This is the main objective of this study: to analyze the barriers faced by family farmers (FF) that affect its transformation into a rural entrepreneur (RR). To study these two groups, we interviewed and applied a structured questionnaire to a convenience sample, non-probabilistic, selected by the criterion of typicality of fourteen farmers who started their business in Southern Brazil. For these The analysis showed that the barriers to rural entrepreneurship were associated with lack of leadership and ability to take risks, and emphasized the importance of the family, social networks and formal education in the development of FF. We conclude that the FF can't be regarded as typical Schumpeterian entrepreneurs, but some points have become critical to the implementation of public policies: a contingency approach; prioritize the targeting of resources to more entrepreneurial profiles; promote the objective and subjective evaluations of the results of resource allocation; strengthen training programs, management education and business incubators.
\end{abstract}

Keywords: Rural Entrepreneurship; Entrepreneur Behavior; Innovation, Family Agriculture. 
Análise das Barreiras que Dificultam a Transformação do Agricultor Familiar em Empreendedor Rural no Contexto Brasileiro

\section{ANÁLISIS DE LOS OBSTÁCULOS A LA TRANSFORMACIÓN DE LOS AGRICULTORES FAMILIARES EN EMPRENDEDOR RURAL EN CONTEXTO DE BRASIL}

\section{RESUMEN}

Pese a la importancia de la agricultura familiar, hasta mediados de los años 90 , los agricultores brasileños tenían poco o ningún acceso al crédito y las políticas públicas ya existentes a menudo no cumplen con las necesidades de esta población. En 1996, el gobierno brasileño creó el PRONAF - Programa Nacional de Agricultura Familiar, el primer programa de crédito rural diseñado exclusivamente para los agricultores familiares (AF), que a pesar de numerosas cualidades, se enfrenta a desafíos relacionados con las características socioculturales y psicosociales de los agricultores, que no siempre pueden incorporar los comportamientos necesarios para ser empresarios rurales ( ER) en una industria que demanda cada vez más por la innovación y el desarrollo. Este es el objetivo principal de este estudio: analizar las barreras que enfrentan los agricultores familiares (AF) que afectan a su transformación en un empresario rural (ER). Para el estudio de estos dos grupos, se entrevistó y aplicó un cuestionario estructurado a una muestra de conveniencia, no probabilística, seleccionada por el criterio de la tipicidad de catorce agricultores que comenzó su negocio en el sur de Brasil. El análisis mostró que las barreras para el emprendimiento rural estaban asociados con la falta de liderazgo y la capacidad de asumir riesgos, y destacó la importancia de la familia, las redes sociales y la educación formal en el desarrollo de AF. Llegamos a la conclusión de que el AF no puede ser considerado como empresarios típicos schumpeterianos, pero algunos puntos son importantes e críticos para la implementación de políticas públicas: un enfoque de contingencia dirigiendo los recursos hacia perfiles más empresariales; fomentar las evaluaciones objetivas y subjetivas de los resultados de la asignación de recursos; fortalecer los programas de capacitación, la educación de gestión e incubadoras de empresas .

Palabras clave: Emprendimiento Rural; Comportamiento Emprendedor; La Innovación; La Agricultura Familiar.

\footnotetext{
${ }^{1}$ Doutora em Administração pela Universidade de São Paulo - USP. Professora da Pontifícia Universidade Católica do Rio de Janeiro - PUC/RJ. Brasil. E-mail: patomei@iag.puc-rio.br

${ }^{2}$ Mestre em Administração pela Pontifícia Universidade Católica do Rio de Janeiro - PUC/RJ. Brasil. E-mail: dalimarj@gmail.com
} 


\section{O EMPREENDEDOR RURAL E A INOVAÇÃO NO CONTEXTO BRASILEIRO}

\section{INTRODUÇÃO}

Apesar de a agricultura mundial empregar $65 \%$ da população mundial e ser responsável por $75 \%$ do seu comércio doméstico (UNIDO, 2011), a maioria dos recursos e políticas públicas está direcionada ao desenvolvimento urbano.

Esta falta de balanceamento se acentua em economias em desenvolvimento prejudicando não apenas as populações rurais, como todo o processo econômico e social. Nestes países, de cada quatro pessoas pobres, três situam-se em zonas rurais e dependem direta ou indiretamente da agricultura (Fauth, 2006). Essas pessoas, devido as suas características psicossociais, cultura e comportamentos pouco empreendedores, muitas vezes têm dificuldades de deixar de conviver com processos tradicionais de trabalho, afetando a sua produtividade e o desenvolvimento econômico e social. (Ozgen e Minsky, 2007).

No Brasil, o agronegócio como um todo, considera além da agropecuária propriamente dita, as atividades a montante ("antes da porteira") e a jusante ("depois da porteira"), e gera um a cada três empregos no Brasil, ou seja, 18 milhões de emprego ou $30 \%$ da população economicamente ativa (Sampaio Filho, 2005; Guilhoto,2004). Dentro deste contexto a importância da agricultura familiar reforça os dados encontrados em nações em desenvolvimento, na medida em que emprega $77 \%$ das 17,3 milhões de pessoas ocupadas no meio rural brasileiro e é responsável por $38 \%$ do valor bruto da produção agropecuária nacional e $70 \%$ dos alimentos consumidos pelas famílias brasileiras em todo País. (Dalmolin, 2009).

Assim sendo, o fortalecimento da agricultura familiar tem sido visto como uma forma de desenvolvimento sustentável, pois contribui para a criação de atividades agrícolas e não agrícolas e, com isso, colabora para que as famílias permaneçam ou se fixem no meio rural, minimizando o êxodo ocorrido no final da década de 80 e suavizando um quadro nefasto de grande concentração de terras e riquezas no campo e desordenado processo de urbanização (Fauth, 2008).

Mas, apesar da evidente importância da agricultura familiar, até meados da década de 90, os pequenos agricultores brasileiros tinham pouco ou nenhum acesso ao crédito e as políticas públicas existentes muitas vezes não atendiam aos anseios desta população.

Diante deste quadro, em 1996, o governo Fernando Henrique Cardoso criou o PRONAF -
Programa Nacional da Agricultura Familiar - que foi o primeiro programa de crédito rural voltado exclusivamente para a agricultura familiar. Este programa tem apresentado um crescimento quantitativo significativo em termos de recursos e abrangência ao longo dos três últimos governos nacionais,mas, qualitativamente ainda enfrenta desafios complexos relacionados a aspectos sócio-culturais e características psicossociais dos agricultores, que nem sempre conseguem incorporar os comportamentos necessários para serem empreendedores num setor que cada vez mais demanda por inovação e desenvolvimento.

Este é o principal objetivo deste trabalho: analisar quais as barreiras enfrentadas pelo agricultor familiar (AF) que dificultam ou impedem sua transformação em empreendedor rural (ER), isto é, por que alguns agricultores conseguem ultrapassar obstáculos e se desenvolvem, ampliando seus empreendimentos, e outros não conseguem substituir técnicas rudimentares de produção de subsistência e de consumo?

A rápida urbanização e a concentração da maior parte da população brasileira nas áreas metropolitanas têm levado os meios de comunicação e os estudiosos a dar pouco destaque ao que ocorre no meio rural, tanto no que tange à questão do emprego e do trabalho (Schneider, 2008), quanto na própria melhoria da qualidade de vida daqueles que dependem do campo (Estevan, 2010).

As ideias desenvolvidas neste artigo ajudam na reflexão desta temática, importante e carente de pesquisas e trabalhos acadêmicos. Para tanto, inicialmente faremos uma breve contextualização do empreendedorismo rural, da agricultura familiar e do perfil do empreendedor enfatizando as suas oportunidades e desafios, e características comportamentais importantes para o seu processo de inovação e desenvolvimento. Num segundo momento faremos uma análise de um estudo do caso brasileiro, onde detalharemos os aspectos metodológicos da pesquisa e seus resultados que serão comparados com a literatura do tema. Por fim, serão feitas algumas sugestões que auxiliem na reflexão e na formulação de políticas que incentivem o empreendedorismo rural.

\section{INOVAÇÃO E DESENVOLVIMENTO NO EMPREENDEDORISMO RURAL}

Relacionar a questão do empreendedorismo rural e da agricultura familiar a palavras como desenvolvimento e inovação num primeiro momento pode parecer algo inconcebível. O que tem de inovador um $\mathrm{AF}$, que pratica atividades no meio rural em área inferior a quatro módulos fiscais, utilizando 
Análise das Barreiras que Dificultam a Transformação do Agricultor Familiar em Empreendedor Rural no Contexto Brasileiro

predominantemente mão-de-obra da própria família, vivendo com uma renda originada de atividades econômicas vinculadas ao próprio estabelecimento que é dirigido por sua família, quando comparado a um ER que exerce controle sobre a sua produção e realizando uma mudança no seu processo produtivo?

Para autores comportamentais como McClelland (1971) e Filion (1997) esta associação é de fato possível, conforme veremos na evolução da literatura de empreendedorismo a seguir.

O termo empreendedorismo foi objeto de estudos durante vários séculos, tendo recebido uma maior atenção no século XX, principalmente a partir dos anos oitenta. Desde o século XVII, quando ocorreu a primeira concepção mais clara sobre o termo, até meados dos anos sessenta, o campo do empreendedorismo foi dominado pelos economistas, que acreditavam que este tinha impacto direto no crescimento econômico de uma determinada região. Deste grupo, vale destacar Schumpeter (1934) que entre outras contribuições, introduziu a palavra inovação à temática qualificada como uma nova utilização dos recursos disponíveis, diferente da forma tradicional; e Shane e Venkataraman (2000) que enfatizaram o papel dos empreendedores como agentes do aumento da eficiência e da alocação de recursos na economia.

No entanto, em relação ao empreendedorismo rural, temos uma situação paradoxal: por um lado temos áreas de baixo desenvolvimento socioeconômico, com infraestrutura inadequada, baixos níveis educacionais, trabalhadores com baixa qualificação, baixa renda e uma cultura que não incentiva as atividades de risco e crescimento de negócios (Kulawczuk, 1998; Petrin e Gannon, 1997); e, por outro lado, no final de século XX e início do novo milênio, aumentaram os desafios e exigências de gerenciamento das propriedades rurais para que se tornem competitivas (Zimmermann, 1992).

Neste contexto emerge o AF: o agente de transformação da realidade socioeconômica que deve fazer uso das tecnologias disponíveis na propriedade rural para atender às necessidades e pressões ambientais, inserido numa cultura onde a inovação é vista como uma nova combinação dos recursos já disponíveis. Para este AF o simples fato de extrair o leite da vaca e transformá-lo em queijo já significa uma inovação, completamente diferente, da perspectiva do empreendedor urbano na qual a transformação do leite em queijo seria considerada como um processo industrial comum, não devendo ser enquadrada como um processo inovador.

Para melhor compreender esses desafios, em meados da década de sessenta, a corrente comportamentalista de empreendedorismo foca em estudar a figura do empreendedor, relacionando o seu sucesso com suas características e comportamentos. Vários pesquisadores desenvolveram seus estudos com base nestas premissas, conforme é resumido no quadro de Carland et al. (1984) reproduzido a seguir:

Tabela 1 - Características dos empreendedores

\begin{tabular}{|l|l|}
\hline \multicolumn{1}{|c|}{ AUTOR } & \multicolumn{1}{|c|}{ CARACTERÍSTICAS } \\
\hline Sutton (1954) & Desejo de responsabilidade \\
\hline Davids (1963) & Ambição; Desejo de independência; Responsabilidade; Auto-confiança \\
\hline Pickle (1964) & $\begin{array}{l}\text { Impulso intelectual; Interesse por relações humanas; Habilidade para comunicação; } \\
\text { Conhecimento técnico }\end{array}$ \\
\hline Palmer (1971) & Mensuração de risco \\
\hline Hornaday \& Aboud (1971) & $\begin{array}{l}\text { Necessidade de realização; Autonomia; Agressividade; Poder; Reconhecimento; Inovação; } \\
\text { Independência }\end{array}$ \\
\hline Winter (1973) & Necessidade de poder \\
\hline Borland (1974) & Controle interno \\
\hline Liles (1974) & Necessidade de realização \\
\hline Gasse (1977) & Orientação por valores pessoais \\
\hline Timmons (1978) & $\begin{array}{l}\text { Auto-confiança; Orientação para objetivos; Propensão a riscos moderados; Controle interno; } \\
\text { Criatividade; Inovação }\end{array}$ \\
\hline Welsh \& White (1981) & $\begin{array}{l}\text { Necessidade de controle; Interesse em assumir responsabilidades; Auto-confiança; Interesse por } \\
\text { desafios; Propensão a riscos moderados }\end{array}$ \\
\hline $\begin{array}{l}\text { Dunkelberg \& Cooper } \\
\text { (1982) }\end{array}$ & Orientado para o crescimento; Independente \\
\hline
\end{tabular}

Fonte: adaptado de Carland et al., 1984 
Análise das Barreiras que Dificultam a Transformação do Agricultor Familiar em Empreendedor Rural no Contexto Brasileiro

Dentro desta corrente comportamental, dois modelos clássicos se destacaram: o de McClelland (1971) e o de Fillion (1997).

Segundo McClelland (1971) existem três características básicas interligadas que identificam o perfil empreendedor: o empreendedor possui uma grande motivação para a realização; para se realizar, está disposto a assumir riscos e se assume risco, é porque tem autoconfiança.

Tabela 2 - Doze Características básicas que identificam o perfil empreendedor segundo McClelland

\begin{tabular}{|l|l|}
\hline \multicolumn{1}{|c|}{ CARACTERÍSTICA } & \multicolumn{1}{c|}{ COMPORTAMENTO } \\
\hline Necessidade de realização & Busca alcançar seus objetivos a qualquer preço, com honestidade e ética \\
\hline Disposição para assumir riscos & Assume e gerencia riscos, mas não é um aventureiro \\
\hline Autoconfiança & Acredita em si mesmo \\
\hline Busca de oportunidades e iniciativa & $\begin{array}{l}\text { Está atento às oportunidades que a vida lhe apresenta e possui vontade de agarrá- } \\
\text { las }\end{array}$ \\
\hline Busca de informações & $\begin{array}{l}\text { Busca se informar sobre tudo o que pode ser melhor para a sua vida e para o seu } \\
\text { negócio }\end{array}$ \\
\hline Estabelecimento de metas & Capacidade para traçar objetivos \\
\hline Exigência de qualidade e eficiência & Busca a melhor forma de se fazer algo \\
\hline Planejamento e monitoramento sistemático & Decide antecipadamente o que fazer, como, quando e quem deve fazer \\
\hline Persistência & Tem garra para vencer obstáculos \\
\hline Persuasão & Capacidade de influenciar as pessoas e de negociar \\
\hline Comprometimento & É dedicado, tem orgulho daquilo que faz \\
\hline Independência e autoconfiança & Acredita em si mesmo e na sua capacidade \\
\hline
\end{tabular}

Fonte: adaptado de McClelland, 1971

Filion (1997) afirma que para conhecermos o empreendedor é preciso identificar suas habilidades e competências; e os métodos de aprendizado pessoal e organizacional necessários para se ajustar adequadamente às mudanças nas atividades relacionadas ao negócio, já que os empreendedores são influenciados pelo período e o lugar em que vivem.

Tabela 3 - Quinze Características comumente encontradas no empreendedor segundo Filion

\begin{tabular}{|l|l|}
\hline \multicolumn{1}{|c|}{ CARACTERISTICA } & \multicolumn{1}{c|}{ COMPORTAMENTO } \\
\hline Alto nível de energia & Tem garra e sabe concentrar esforços para alcançar resultados \\
\hline Autoconfiança & Acredita em si mesmo \\
\hline Capacidade de aprendizagem & Capacidade de se desenvolver \\
\hline Capacidade de correr riscos moderados & Assume e gerencia riscos, mas não é um aventureiro \\
\hline Inovação & Capacidade de transformar ideias criativas em práticas \\
\hline Liderança & Capacidade de influenciar e de atrair seguidores \\
\hline Reconhecimento de oportunidades & Capacidade de perceber uma nova oportunidade que surge \\
\hline Independência & Capacidade de fazer tudo sozinho \\
\hline Orientação para resultados & Persegue o melhor desempenho para si próprio e para o seu negócio \\
\hline Otimismo & Pensa positivo \\
\hline Habilidade na utilização de recursos & $\begin{array}{l}\text { Possui conhecimento e experiência para utilizar todos os recursos } \\
\text { disponíveis }\end{array}$ \\
\hline Persistência & Tem garra para vencer obstáculos \\
\hline Sensibilidade com o próximo & Se preocupa com o bem estar das pessoas \\
\hline Tendência a confiar nas pessoas & Acredita na sinceridade das pessoas \\
\hline Tolerância a incertezas & Capacidade de tomar decisões mesmo sem conhecer o futuro \\
\hline
\end{tabular}

Fonte: adaptado de Filion, 1997 
Nos dias atuais, para falarmos do fortalecimento do empreendedorismo precisamos levar em conta não apenas as características do empreendedor, mas também sua capacidade de empreender e o contexto ambiental que favoreça e amplie a confiança dos atores locais em suas atividades empreendedoras (Locke, 2001).

De acordo com Acs e Kallas (2007), quando pessoas de segmentos socioeconômicos mais vulneráveis decidem abrir "seu próprio negócio sem as qualificações necessárias, como educação, capital financeiro e contatos sociais, em muitos casos, fracassam" (Acs e Kallas, 2007, p. 22).

Especificamente no que diz respeito ao empreendedor rural, inovação e competitividade não são apenas atributos isolados de cada AF, mas, sobretudo resultados sistêmicos de suas relações sociais (Sepúlveda et al, 2003).

\section{AGRICULTURA FAMILIAR BRASILEIRA E O PRONAF}

A produção familiar agrícola brasileira vem se reproduzindo ao longo das gerações e se adaptando aos movimentos da conjuntura sócio-econômica, independentemente dos regimes políticos, das diferenças geográficas e territoriais (Jean, 1993). Ela foi dominada por quase dois séculos pela agricultura patronal, constituída de grandes latifúndios e de trabalho assalariado (Fauth, 2006) que apoiada pelos avanços tecnológicos, não emprega um número significativo de trabalhadores, dificultando a distribuição de renda e a inclusão social.

Dos anos 60 aos anos 80, observamos que este modelo de desenvolvimento veio acompanhado de êxodo rural, forte loteamento do meio urbano e o agravamento das desigualdades sociais entre o campo e a cidade.

No início da década de 1990, o Brasil se deparava com o fortalecimento dos movimentos sociais rurais, o que mobilizou a esfera governamental para o desenvolveimento de políticas públicas voltadas a resolver os problemas relacionados às questões agrárias.

Foi neste contexto que, em 1996, o Governo criou o PRONAF - Programa Nacional da Agricultura Familiar - com o objetivo de manter o homem no campo, por meio de uma política pública específica e diferenciada para a agricultura familiar.

O PRONAF foi um marco na história das políticas públicas brasileiras exatamente por associar o acesso ao agricultor familiar a um ativo fundamental: o crédito. (Abramovay e Veiga, 1999).

\subsection{Metodologia de Pesquisa}

Para a análise das barreiras que impactam a transformação de um agricultor familiar (AF) em um empreendedor rural. (ER) segundo suas características comportamentais, capacidade de empreender e contexto ambiental, escolhemos uma Cooperativa de Crédito Rural Brasileira denominada CRESOL, que indicou uma amostra por conveniência, não probabilística, selecionada pelo critério da tipicidade de catorze agricultores (seis caracterizados como AF e oito como ER) considerados representativos da população-alvo, que iniciaram o seu negócio há mais de 42 meses na Região Sul do Brasil e que favoreciam a intenção da pesquisa (Cozby, 2006) descritos na tabela a seguir. 
Análise das Barreiras que Dificultam a Transformação do Agricultor Familiar em Empreendedor Rural no Contexto Brasileiro

Tabela 4 - Composição da amostra de entrevistados

\begin{tabular}{|c|c|c|c|c|c|}
\hline $\mathbf{N}$ & IDADE & SEXO & GRAU DE INSTRUÇÃO & SETOR DE ATUAÇÃO & ER OU AF \\
\hline 1 & 28 & $\mathrm{~F}$ & $2^{\circ}$ grau & Panificação & ER \\
\hline 2 & 39 & $\mathrm{~F}$ & $2^{\circ}$ grau & Agroturismo & ER \\
\hline 3 & 48 & M & $1^{\circ}$ grau & Fruticultura & $\mathbf{A F}$ \\
\hline 4 & 37 & M & $1^{\circ}$ grau & Pecuária leiteira & $\mathbf{A F}$ \\
\hline 5 & 44 & M & $2^{\circ}$ grau & Cana de açúcar & ER \\
\hline 6 & 36 & M & $1^{\circ}$ grau & Embutidos & ER \\
\hline 7 & 50 & M & $1^{\circ}$ grau & Fruticultura e Comércio & $\mathbf{A F}$ \\
\hline 8 & 45 & $\mathrm{M}$ & Superior & Vinicultura & ER \\
\hline 9 & 38 & $\mathrm{M}$ & $1^{\circ}$ grau & Agroturismo & ER \\
\hline 10 & 25 & M & Curso Técnico & Pecuária leiteira & $\mathbf{A F}$ \\
\hline 11 & 49 & M & $1^{\circ}$ grau & Avicultura & $\mathbf{A F}$ \\
\hline 12 & 51 & $\mathrm{M}$ & $1^{\circ}$ grau & Agroturismo & ER \\
\hline 13 & 37 & M & $1^{\circ}$ grau & Avicultura & $\mathbf{A F}$ \\
\hline 14 & 47 & M & $2^{\circ}$ grau & Laticínios + Doces & ER \\
\hline
\end{tabular}

Fonte: Elaborado pelos autores

Para a coleta de dados foram realizadas entrevistas em profundidade e aplicados questionários semi-estruturados, ao longo de dois meses no segundo semestre de 2009 e dois meses no primeiro semestre de 2010. Optou-se pelo anonimato para que os entrevistados se sentissem mais à vontade em participar da pesquisa.

Para cada entrevistado foram necessários de dois a três dias de contato pessoal, facilitados pelas pesquisadoras que ajudavam a preencher os questionários e gravavam os depoimentos.

Para o preenchimento dos questionários, num primeiro momento as perguntas fechadas solicitavam ao entrevistado que avaliasse numa escala Likert se ele possuía ou não as características e comportamentos encontrados em empreendedores nos estudos de McClelland (1971) e de Filion (1997).

Essas afirmações eram complementadas com um "Teste de Perfil Empreendedor" adaptado do modelo do SEBRAE disponível em http://www.sebrae.com.br/atendimento/teste-aqui-seuperfil-empreendedor, que constituiu uma importante ferramenta para que os entrevistados se descontraíssem e relatassem casos, e fossem avaliados diante de situações simuladas.

As respostas desses questionários foram tabuladas e agrupadas segundo as características comportamentais, e analisadas qualitativamente como complemento das entrevistas, favorecendo a comparação entre os dois grupos (AF e ER).

Para as entrevistas, as questões foram adaptadas do artigo publicado por Man et Lau (2000) que avalia as competências empreendedoras dos proprietários / gerentes do setor de serviços de Hong Kong segundo: iniciativa e coragem, experiência de vida, persistência, apoio da família, exemplo das experiências de terceiros, necessidade de crescer e dificuldades no gerenciamento do negócio.

As entrevistas, por contemplarem expressões verbais contidas nas narrativas das pessoas, passaram por uma análise de conteúdo de modo a se incluir as variáveis relevantes ao processo de empreender em categorias temáticas escolhidas segundo o modelo de Gartner (1985) que considera que a criação de um novo negócio integra quatro grandes perspectivas em termos de empreendedorismo: (a) Indivíduo(s): a(s) pessoa(s) envolvida(s) na criação do novo empreendimento; (b) Organização: o tipo de empresa que está sendo criada; (c) Ambiente: a situação ao redor e sua influência na nova organização; e (d) Processo de criação de um novo empreendimento: as ações realizadas pelo(s) indivíduo(s) para iniciar o novo empreendimento conforme resumido na figura 1 : 
Análise das Barreiras que Dificultam a Transformação do Agricultor Familiar em Empreendedor Rural no Contexto Brasileiro

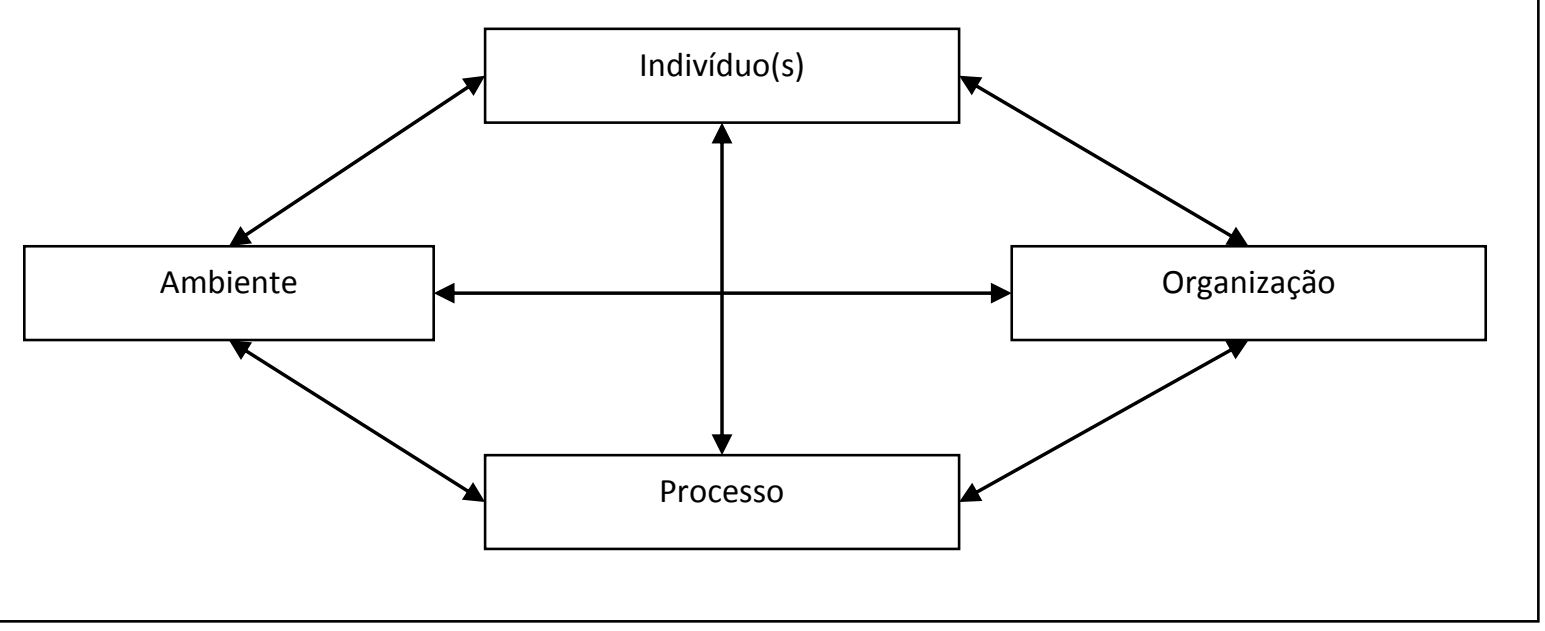

Figura 1- Modelo: Criação de novos empreendimentos.

Fonte: Gartner (1995)

Para a análise comparativa dos dois grupos (AF e ER) foram consideradas apenas três categorias deste modelo: indivíduo (características comportamentais, condições de vida, persistência, e necessidade de crescer); ambiente (exemplo das experiências de terceiros, base industrial, a disponibilidade de recursos financeiros e o papel do Governo) e processo, (capacidade do empreendedor em perceber uma oportunidade de negócio, o papel dos amigos e da família, e a educação formal).
A categoria organização não foi abordada, já que as variáveis apontadas pelo autor pouco ou nada se relacionam com a agricultura familiar e o empreendedorismo rural.

Portanto para alcançar os objetivos do estudo e analisar as barreiras enfrentadas pelo agricultor familiar (AF) que dificultam ou impedem sua transformação em empreendedor rural (ER), a partir das categorias descritas no modelo de Gartner (1995) temos o construto desta pesquisa resumido na tabela a seguir:

Tabela 5 - Construto da Pesquisa

\begin{tabular}{|l|l|}
\hline \multicolumn{1}{|c|}{ CATEGORIA } & \multicolumn{1}{|c|}{ VARIAVEIS } \\
\hline $\begin{array}{l}\text { Individuo: a(s) pessoa(s) } \\
\text { envolvida(s) na criação do } \\
\text { novo empreendimento }\end{array}$ & $\begin{array}{l}\text { Características comportamentais como autoconfiança, condições de vida, persistência, } \\
\text { necessidade de crescer, busca de informações, exigência de qualidade, comprometimento, } \\
\text { alto nível de energia, necessidade de realização, poder de persuasão, capacidade de } \\
\text { liderança, busca por inovação e otimismo como insumos para os empreendedores. }\end{array}$ \\
\hline $\begin{array}{l}\text { Ambiente:a situação ao ao } \\
\text { redor e sua influência na } \\
\text { nova organização }\end{array}$ & $\begin{array}{l}\text { Presença de empreendedores experientes e a existência de uma força de trabalho } \\
\text { tecnicamente habilitada, exemplo das experiências de terceiros, base industrial, a } \\
\text { disponibilidade de recursos financeiros e o papel do Governo como insumos para os } \\
\text { empreendedores. }\end{array}$ \\
\hline $\begin{array}{l}\text { Processo de criação de um } \\
\text { novo empreendimento: as } \\
\text { ações realizadas pelo(s) } \\
\text { indivíduo(s) }\end{array}$ & $\begin{array}{l}\text { Compreensão do desenvolvimento rural como um processo que exige o conhecimento do } \\
\text { público que se pretende atingir, sua capacidade em perceber uma oportunidade de negócio, } \\
\text { de utilizar o apoio dos amigos, da família e a educação formal como insumos para os } \\
\text { empreendedores. }\end{array}$ \\
\hline
\end{tabular}

Fonte: Elaborado pelos autores. 


\section{ANÁLISE DOS RESULTADOS}

\subsection{Categoria: Indivíduo}

Tanto na visão de McClelland (1971) quanto na de Filion (1997), características como autoconfiança, busca de informações, exigência de qualidade, comprometimento, alto nível de energia e otimismo são importantes para os empreendedores, corroborando com vários estudos sobre o tema, dos quais destacamos o trabalho de Jyoti et al (2011) no qual os autores analisam como estes fatores comportamentais impactam na orientação e satisfação de mulheres empreendedoras na Índia rural.

$\mathrm{Na}$ presente pesquisa estas características comportamentais também se mostraram como típicas dos dois grupos, independentemente deste ser ou não empreendedor. Mas, identificamos no grupo AF alta aversão ao risco e falta de características como necessidade de realização, poder de persuasão, capacidade de liderança e busca por inovação como possíveis barreiras à sua transformação em ER.

Esta aversão ao risco está relacionada a uma herança cultural do grupo $\mathrm{AF}$, historicamente focado na agricultura de subsistência, um processo que permitia maior individualidade e que não demandava grandes responsabilidades. Ela reflete um traço cultural forte da cultura brasileira, e da maioria das culturas de países da America Latina que Hofstede (1980) chamou de aversão à incerteza: grau de ameaça percebido por membros de uma cultura em situações incertas ou desconhecidas.

Conforme constatamos no site http://geerthofstede.com/ o Índice de Aversão ao Risco (UAI) do Brasil (76) é considerado alto quando comparado a países africanos (52), ao Reino Unido (35), Dinamarca (23), e baixo quando comparado a países europeus como Grécia (112) e Portugal (104) por exemplo. Brasileiros em geral têm necessidade de previsibilidade, sentem desconforto ou insegurança com riscos como traço cultural, e para os AF este traço é acentuado pelas características do setor agrícola. Os depoimentos a seguir ilustram estas conclusões:

"Eu não sou de correr riscos assim em termos financeiros, em termos de automóveis, essas coisas assim. " (AF 13)

"Eu tento fazer o passo que a perna alcança. [...] Eu sempre fui cauteloso. Não gostaria de estar aí me arriscando não. ” (AF 3)
Esta questão de aversão ao risco também foi identificada como barreira para a modernização de cooperativas e introdução de tecnologias empreendedoras em pesquisa feita por Lassithiotaki (2011) com mulheres agricultoras rurais gregas, que se recusavam em aprender como agir gerencialmente por medo e insegurança diante da instabilidade do livre mercado, confirmando o alto índice de aversão à incerteza identificada por Hofstede (1980) na cultura grega.

Ter ou não necessidade de realização não constituiu ser ou não empreendedor para todo o grupo pesquisado. A diferença está no significado de "estar realizado" para o grupo AF e ER. O grupo ER possui um grau de exigência superior ao grupo AF, ou seja, o empreendedor para se realizar plenamente precisa de mais coisas que o não-empreendedor. Esse fato, associado ao maior grau de acomodação do AF em relação ao ER, estabelece uma diferença comportamental significativa entre esses dois grupos.

Os dois grupos demonstraram vontade de crescer, ter uma renda maior, mas não conseguem superar a sua visão imediatista, estabelecer metas e dimensionar o seu sonho num plano estratégico. Alguns relatos retratam bem esta realidade:

"Na agricultura é assim: você faz os planos, mas digamos que 5 a 10\% depende de você. O restante depende do clima, da natureza, porque é uma cultura de risco muito grande. Então foge do seu controle. ” (ER 8)

"A gente tenta traçar as metas por mês. Esse mês a gente tem compensar o que não vendemos o mês passado. ", (AF 1)

A busca de oportunidades e inovação está fortemente relacionada com a aversão ao risco. Se por um lado o AF afirma estar atento às oportunidades que a vida lhe apresenta, ele só programa a mudança se tiver certeza de que será sucesso. Os ERs também mostraram ser avessos ao risco, mas para eles um risco moderado é passível de aceitação.

As aspirações no que diz respeito às condições de vida influenciaram significativamente os comportamentos diferenciados dos grupos AF e ER. Se por um lado, para o grupo ER o desejo de prosperar na vida e de oferecer uma condição de vida melhor para a sua família alavancou a motivação e o impulso de empreender, o mesmo não ocorreu com o grupo $\mathrm{AF}$, que demonstrou estar satisfeito com a sua vida modesta e tranquila. 
Em termos de motivação, os agricultores entrevistados podem ser classificados em dois grandes grupos: aqueles que abriram o negócio porque correram atrás de seu sonho e aqueles que abriram o negócio porque tinham a necessidade de crescer para conseguir sustentar a sua família, sendo este último o de maior ocorrência.

Estas características encontradas no grupo ER reforçam que a motivação é fundamental para a criação do novo empreendimento, já que conforme coloca $\mathrm{Yu}$ (2001) até mesmo a mais óbvia oportunidade pode ser ignorada por um indivíduo que não está motivado ou preparado para vê-la, isto é, que não possui, não sabe se possui ou nunca estimulou sua perspicácia empreendedora. Pesquisas de Tomei et al (2008) e Bottino et al (2006) sobre o papel da motivação e do sonho como o combustível necessário à ação empreendedora também confirmam estes resultados. Entre os entrevistados do grupo ER, todos possuíam um motivo para empreender: proporcionar condições de vida melhores para sua família. Juntamente com esta causa, alguns também possuíam um sonho: manter a família unida no campo.

\subsection{Categoria: Ambiente}

Em relação ao ambiente observamos que a presença de empreendedores experientes e a existência de uma força de trabalho tecnicamente habilitada foram fatores importantes para o comportamento do grupo ER. O agricultor entende muito das técnicas relacionadas ao seu trabalho propriamente dito, mas quando a habilidade diz respeito a atividades mais gerenciais, o seu conhecimento é escasso. Isso possivelmente se deve a outras variáveis elencadas por Gartner (1995) como a falta de proximidade de instituições de ensino, as dificuldades de acesso a clientes, novos mercados e serviços de suporte. Em relação ao acesso a clientes, cabe mencionar que os agricultores familiares têm como principal mercado consumidor a feira do produtor que acontece em praticamente todos os municípios e costuma ser o ponto de partida dos AF para uma atividade empreendedora, ou seja, o primeiro local em que eles expõem os seus produtos. $O$ sucesso nesta feira alimenta a vontade para conquistar novos mercados.

Inúmeras pesquisas com empreendedores confirmam o papel do ambiente segundo seus diferentes componentes no desenvolvimento do empreendedores. Nos trabalhos de Hills et al (1999) e Hills \& Shrader (1998) os autores constataram que para identificar uma boa oportunidade é preciso imergir numa indústria ou mercado particular. Estas conclusões são reforçadas nos trabalhos de Bygrave (1997) que afirmam que $90 \%$ dos novos negócios de alto potencial norte-americanos foram iniciados na mesma indústria ou próxima a que o empreendedor atuou previamente e de Bhidé (2000) que demonstraram que a maioria dos empreendedores de sucesso imitou ou adaptou uma ideia que encontrou durante seu emprego anterior, ou seja, empreendedores do tipo spin off, percebendo a descontinuidade de tecnologias. No que diz respeito ao papel da experiência é interessante destacar os trabalhos de Shane (2000) que enfatizaram que a experiência prévia alavanca o reconhecimento do valor de uma nova informação que poderá se tornar uma nova oportunidade; as pesquisas de Alsos \& Kaikkonen (2004) e de Correa e Vale (2014) que apontaram que a experiência e vivência do empreendedor, assim como sua rede social de relacionamentos podem contribuir para que ele tenha a percepção de que uma ideia possa se constituir numa oportunidade potencial , os estudos de Beduschi e Abramovay (2003) que apontaram que a falta de experiência, qualificação profissional, escassez de exemplos virtuosos dificulta a criação de novos empreendimentos, confirmando que "o desenvolvimento do espírito de empresa repousa, ao que tudo indica, sobre um fenômeno de imitação" (OCDE, 2003, p. 55) e os trabalhos de Storopolli et al. (2013); Raupp e Beren (2009); Autio et al.(2011) e Zahra et al.(2006) que enfatizaram a importância de aprofundar o conhecimento sobre a formação, o desenvolvimento e o estabelecimento de capacidades dos empreendedores.

No caso da agricultura familiar, os entrevistados dos dois grupos confirmam as conclusões referentes ao aspecto intuitivo e não linear do processo de empreender (Lumpkin et al., 2001), da heterogeneidade da sensibilidade de cada indivíduo na percepção de oportunidades voltadas para a criação de um novo valor (Ardichvili et al., 2003) e das dificuldades da sucessão profissional no campo (Silvestro et al., 2001) conforme reforça o depoimento a seguir:

"Não tenho o conhecimento total de colocar tudo certinho no papel. A gente faz tudo aos trancos e barrancos. [...] Precisaria fazer mais umas capacitações. ” (sic) (ER 1)

A pesquisa confirmou os estudos de Ibáñez et.al. (2004) quando identificou que os AF têm tido muita dificuldade em internalizar que estão sujeitos a um mercado cada vez mais exigente, que torna imprescindível considerar as características impostas pela demanda e tornar competitiva a produção familiar para a obtenção de sustentabilidade do seu negócio.

Por fim, todos os ER entrevistados iniciaram o seu negócio com capital próprio por medo e insegurança, recorrendo num segundo momento à ajuda da cooperativa de crédito ou de bancos cautela, conforme ilustram os depoimentos a seguir: 
"Não pegamos (sic) financiamento no início porque tinha medo de não conseguir pagar. [...] Entrava um dinheirinho nós comprava (sic) uma máquina. Entrava outro comprava uma forma. " (ER 1)

"Eu sempre fui um cara assim, oh, eu não dou um passo se eu não tiver certeza que eu alcance. [...] Eu tenho muito medo de divida. Então eu só faço se eu tiver certeza que eu já tenho dinheiro pra pagar. " (sic) (ER 12)

"Quando eu construi isso aqui eu gastei $R \$$ 50.000,00 (cinquenta mil reais). Eu tinha $R \$$ 40.000,00 (quarenta mil), que era recursos próprios meu, daí peguei lá na Cresol. Foram uns cinquenta e poucos mil que eu gastei no primeiro ano."(sic) (AF12)

Esta situação nos remete à análise feita por Abramovay (2003) que reconhece a importância do PRONAF e de outros financiamentos governamentais, mas enfatiza que cada vez mais para a estruturação da lógica de atribuição de recursos públicos é preciso considerar a qualidade dos projetos apresentados, e não apenas levar em conta o julgamento das necessidades sociais das localidades e comunidades que os apresentam.

Como exemplos deste tipo de abordagem, Beduschi e Abramovay (2003) citam o LEADER europeu e o EZEC (Empowerment Zones and Entreprise Communities) norte-americano. No EZEC o importante é a ação de planejamento estratégico de longo prazo, que nem sempre é compatível com o atendimento imediato de necessidades urgentes e no LEADER, se questiona os padrões de inovação e competitividade. (Farrell e Thirion, 2001).

Por fim, um estudo interessante da realidade brasileira da questão foi feito por Kühn (2003) com comunidades gaúchas. A autora ressalta a importância do microcrédito para a agricultura familiar, e que o desenvolvimento rural precisa ser compreendido como um processo que vai além da disponibilização de recursos às famílias, reforçando que é preciso conhecer o público que se pretende atingir, pois o próprio resultado da política corresponde ao uso efetivo das capacitações. Conclui que é necessário ter uma abordagem contingencial da questão, isto é, não existe uma "melhor" forma de acesso: grupos sociais que apresentam características diferenciadas devem ter acesso a formas diferenciadas de políticas públicas.

\subsection{Categoria: Processo}

No que diz respeito à capacidade dos entrevistados perceberem uma oportunidade de negócio, os entrevistados do grupo AF relataram estar atentos às oportunidades que lhes aparecem, mas não demonstraram muita disposição em agarrá-las. Esse resultado pode indicar uma particularidade do empreendedorismo rural, já que ele não acompanha o exposto no Relatório Brasil 2007 GEM (Global Entrepreneurship Monitor) em que constata que a atividade empreendedora por oportunidade em 2007 correspondeu a $56,84 \%$ da população total empreendedora no Brasil naquele ano.

O papel da família e da rede social de amigos é uma das questões mais interessantes encontradas na análise, na medida em que no relato de quase todos os entrevistados (grupo AF e ER) identificou-se um paradoxo entre o "fazer tudo sozinho" e "preciso da família". Os entrevistados afirmaram em seu discurso que eram capazes de fazer tudo sozinhos, mas não assumiram o seu comportamento individualista. Ao contrário, reforçaram o traço cultural de coletivismo identificado na sociedade brasileira (Hofstede, 1980; Barros e Prates, 1996) justificando que não conseguiam ou porque faltava tempo, ou porque na lavoura algumas atividades são desempenhadas simultaneamente, ou porque achavam importante a participação da família, demonstrando que os agricultores são fortemente integrados a grupos coesos, os quais por toda sua vida continuarão a confiar e a proteger em troca de lealdade incontestável, conforme enfocaram Locke (2001) e Sepúlveda et al.(2003). Os depoimentos abaixo ilustram estas questões:

"Tudo sozinho é meio complicado, né? [...] Mas eu não gostaria, eu gostaria de fazer junto com a família. ” (ER12)

"É muita atividade ao mesmo tempo, mas tenho capacidade de fazer tudo sozinha. Gostaria de ter um dia maior para dar tempo de fazer tudo sozinha. " (ER 2)

"Têm coisas que não dá. [...] Tem família também junto, não dá para decidir tudo sozinho. " (AF 4)

A família, os amigos e a influência de famílias vizinhas favorecem a rede de relações que é fundamental para o grupo ER no seu processo de empreender e, em alguns casos serviu de exemplo para os novos empreendedores e em outros funcionou como parceiros na abertura do negócio. Esses resultados colaboram na reflexão do papel do capital social para compreender o agricultor rural enquanto empreendedor, tema de vários estudos sobre 
desenvolvimento rural. (Abramovay, 2000; Veiga, 2003; Schneider, 2008).

De forma análoga encontrada nas pesquisas de Degen (1989), as entrevistas indicaram que o AF privilegia a experiência e a tradição no processo produtivo, aprendida em vivências desde cedo, na maioria das vezes como filho de agricultor. Já o grupo ER está mais aberto para novos conhecimentos e técnicas vivenciadas e trocadas com outros produtores rurais, favorecendo uma rede importante de cooperação e envolvimento associativo, expandindo o seu capital social, fortalecendo os laços de confiança no meio rural e a inclusão destes no mercado.

A reação diante da questão de confiança foi bem interessante, pois ficou evidente que todos os agricultores entrevistados já tiveram algum tipo de decepção por acreditar na sinceridade das pessoas. Alguns relatos são bem interessantes em relação a este assunto:

"Depende, né? [...] Eu gostaria de acreditar em todos, mas não dá, né? ” (ER12)

“Às vezes tu confia (sic) mas com o pé atrás. A gente já levou umas pancadas que não dá para confiar muito. [...] Confio desconfiando. " (ER 5)

“Sou meio desconfiado. ” (AF 10)

“À primeira vista não. Não é possível né (sic) hoje no mundo que nós vivemos (sic) ver uma pessoa e acreditar na sinceridade. Hoje você tá (sic) convivendo às vezes com pessoas 20 anos atrás e quando tu vê apronta, né? (sic) " (AF 13)

Uma situação semelhante é descrita no estudo de Miyazaki et al. (2008) que faz um diagnóstico da agricultura familiar e do empreendedorismo rural no oeste do Paraná e conclui que a valorização da cultura local no meio rural poderia contribuir para promover nos cidadãos índices favoráveis de capital social, gerenciando melhor esta questão fundamental da confiança nas relações interpessoais.

Por fim, a última questão importante referente ao processo de empreender que foi mencionada pelos agricultores e que segundo os entrevistados constitui uma barreira ao empreendedorismo rural é a falta de educação formal, que inibe sua capacidade de liderança, inovação e de aprendizagem.

Os resultados da pesquisa no que diz respeito a este item nos apontam um círculo vicioso que precisa ser revertido: se por um lado, os jovens agricultores filhos de empreendedores que possuem condições, recorrem às unidades de ensino disponíveis na cidade para estudar, por outro lado, os filhos do grupo AF, principalmente de idade mais avançada, ou por falta de condições, ou vontade, ou incentivos, permanecem no campo sem nenhum tipo de estudo, reproduzindo as mesmas limitações que seus pais. Duas experiências brasileiras para gerenciar este círculo vicioso merecem destaque: (1) a do Centro de Empreendimentos Rurais (CER) em Sacramento, Estado de Minas Gerais (Caldas, 2000) que articula programas de formação de jovens empreendedores; fomento e incubação de pequenas agroindústrias e cooperativas; e financiamento de projetos de negócios desenvolvidos nos cursos; (2) a da Casa Familiar Rural (CFR) de Armazém, no Estado de Santa Catarina. (Estevam et al., 2010), uma Organização Não Governamental voltada para a educação de jovens do campo, tendo como especificidade um modelo de ensino inspirado nas experiências das Maisons Familiales Rurales francesa.

\section{CONCLUSÃo}

A partir da análise das barreiras enfrentadas pelo agricultor familiar (AF) que dificultam ou impedem a sua transformação em empreendedor rural (ER), podemos concluir que os agricultores familiares não podem ser considerados como potenciais empresários schumpeterianos típicos, mas, levando em consideração os resultados encontrados, as contribuições teóricas e experiências de sucesso de estudos semelhantes, alguns pontos se tornam fundamentais para a implementação de políticas públicas:

- Uma abordagem contingencial, embasada na premissa de que indivíduos e grupos sociais que apresentam características diferenciadas devem ser tratados de formas diferenciadas.

- O foco estratégico e o posicionamento governamental devem favorecer $o$ gerenciamento combinado das questões que envolvem o indivíduo, o ambiente e o processo de empreender.

- No que diz respeito a fatores ligados ao indivíduo é preciso priorizar o direcionamento de recursos para perfis mais empreendedores selecionados segundo sua motivação e capacidade de lidar com incerteza e risco.

- No que diz respeito a fatores ligados ao ambiente é preciso dar continuidade a um trabalho focado em qualidade, buscando indicadores que favoreçam as avaliações objetivas e subjetivas dos resultados da alocação de recursos.

- No que diz respeito a fatores ligados ao processo é preciso fortalecer e multiplicar programas de formação e incubadoras de negócios, e, incentivar a educação gerencial 
Análise das Barreiras que Dificultam a Transformação do Agricultor Familiar em Empreendedor Rural no Contexto Brasileiro

de forma a favorecer o desenvolvimento da capacidade empreendedora no meio rural e de espaços de socialização de agricultores rurais para criação de capital social.

Por fim, a ampla e importante temática deste estudo demanda investigações futuras que confirmem e complementem os resultados encontrados com modelos quantitativos que favoreçam a generalização e segmentação das diferenças e semelhanças entre os AF e ER.

\section{REFERÊNCIAS}

Abramovay, R. (1998). Agricultura familiar e serviço público: novos desafios para a extensão rural". Cadernos de Ciência \& Tecnologia. v. 15(1), 132152, janeiro/abril.

(2000). O capital social dos territórios: repensando o desenvolvimento rural. Economia Aplicada. 4(2), abril/junho 2000

(2003). Desenvolver os territórios fortalecendo o empreendedorismo de pequeno porte. $1^{\circ}$ Fórum International Território, Desenvolvimento Rural e Democracia. Relatório de Pesquisa, Disponível em: <http://www.fea.usp.br/feaecon//media/fck/File/em preendedorismo_e_desenvolvimento_territorial.pdf >. Acesso em: Novembro/2011.

,VEIGA, J. E. (1999). Novas Instituições para o Desenvolvimento Rural: o Caso do Programa Nacional de Fortalecimento da Agricultura Familiar (PRONAF), IPEA, Texto para Discussão ${ }^{\circ} 641$.

Acs,Z.J. e Kallas,K. (2007), State of Literature on Small-to-medium-sized entreprises and entrepreneurship in low income communities. In G.Yago,J.J. Barth e B.Zeidmand (eds.), Entrepreneurship in Emerging Domestic Markets. (pp.21-46), New York: Springer

Alsos, G. A.; Kaikkonen, V. (2004). Opportunity recognition and prior knowledge: A study of experienced entrepreneurs. NCSB Conference 13th Nordic Conference on Small Business Research.

Ardichvili, A.; Cardozo, R.; Ray, S. (2003). A theory of entrepreneurial opportunity identification and development. Journal of Business Venturing. 18, $105-123$.
Autio, E.; George, G.; Alexy, O. (2011) International Entrepreneurship and Capability Development Qualitative Evidence and Future Research Directions. Entrepreneurship Theory and Practice, January.

Barros, B. T.; Prates, M. A. S. (1996). O estilo brasileiro de administrar. São Paulo: Atlas,

Beduschi, L. C.; Abramovay, R. (2003). Desafios para a gestão territorial do desenvolvimento sustentável no Brasil. Anais do XLI Congresso Brasileiro de Economia e Sociologia Rural (SOBER), Julho de 2003, Juiz de Fora, MG.

Bhidé, A. V. (2000). The Origin and Evolution of New Business. New York: Oxford.

Bottino, C.; Dias C., Korman,S (2006) Empreendedorismo: matéria eletiva - reflexões sobre a experiência em uma universidade - Publit, Rio de Janeiro.

Brockhaus R. H. (1980). Risk Taking Propensity of Entrepreneurs, Academy of Management Journal, 23(3), 509-520.

Bygrave, W. D. (1997). The Portable MBA in Entrepreneurship, 2nd Edition. John Wiley \& Sons, Inc, New York,

Caldas, E. L. (2000). Dicas: idéias para a ação municipal. Instituto Polis. 173.

Carland,J.Hoy F.,Boulton,W., Carland,J. (1984) Differentiating entrepreneurs form small business owners: a conceptuzliation. Academy of Management Review, 9(2), 354-359

Correa,V.S. e Vale, G.M.V.(2014) Redes Sociais, perfil empreendedor e trajetórias, Revista de Administração, Universidade São Paulo, v.49, n.1, p.77-88, jan./fev./mar./ 2014

Dalmolin, R. S. D. (2009). Agricultura familiar: sustentabilidade e consciência ambiental, Feira de Agro Pecuária de Tocantins, AGROTINS.

Davids, L. E. (1963). Characteristics of small business founders in Texas and Geórgia. Athens, Ga.: Bureau of Business Research, University of Geórgia, June.

Degen, R. J. (1989). O empreendedor: fundamentos da iniciativa empresarial. São Paulo: McGraw Hill. 
Análise das Barreiras que Dificultam a Transformação do Agricultor Familiar em Empreendedor Rural no Contexto Brasileiro

Dunkelberg, W. C.; Cooper, A. C. (1982). Entrepreneurial typologies. In: Vésper, K. H. (Ed.) Frontiers of entrepreneurship research. Wellesley: Babson Center for Entrepreneurial Studies.

Estevam, D.; Felipe, D.; Silva, F. N. (2010). Desenvolvimento Local e Agricultura Familiar: um estudo de caso da Casa Familiar Rural de Armazém - SC., II Seminário das Ciências Sociais Aplicadas Desenvolvimento Rural, Educação do Campo e Agricultura Familiar. Disponível em: <http://periodicos.unesc.net/index.php/CSA/article/ view/386/394>. Acesso em: Novembro/2011.

Fauth E. M. (2006). Agricultura Familiar: Força Revigorada, Indicadores Econômicos FEE, Porto Alegre, v. 34, n. 3, p. 25-34, dez.

Farrell, G.; Thirion, S. (2001). A competitividade dos territórios rurais à escala global - Conceber uma estratégia de desenvolvimento territorial à luz da experiência Leader, Inovação em meio rural, Caderno $n^{\circ}$ 6, Fascículo $n^{\circ}$ 5, Observatório Europeu LEADER.

Filion L. J. (1997). From Entrepreneurship to Entreprenology, HEC, The University of Montreal Business School.

(1999). Empreendedorismo: empreendedores e proprietários gerentes de pequenos negócios, In: Revista de Administração, São Paulo 34(2), 5-28, abril/junho.

Gartner,W.B (1985) AConceptual Framework of describing the Phenomenon of New Venture Creation. Academy of Management Review, vol.10,n.4,pp.696-707

Gasse, Y. (1977). Entrepreneurial characteristics and practices: A study of the dynamics of small business organizations and their effectiveness in different environments. Scherbrooke, Quebec: Rene Prince.

Guilhoto, J. J. M.; Silveira, F. G.; Azzoni C. (2004) PIB das Cadeias Produtivas da Agricultura Familiar. [S.1.]: NEAD/MDA, 32p. dez.

(2006). A importância do agronegócio familiar no Brasil. Revista de Economia $e$ Sociologia Rural, Rio de Janeiro, 44(33), 355-382, jul./set.

Hofstede, G. (1980). Culture's Consequences: International differences in work related values. Beverly Hills: Sage.
Hills, G. E.; Lumpkin, G. T.; Singh, R. P. (1999). New Venture Ideas and Entrepreneurial Opportunities: Understanding the Process of Opportunity Recognition. Institute for Entrepreneurial Studies University of Illinois at Chicago.

; Shrader, R. C. (1998). Successful Entrepreneurs' Insights into Opportunity Recognition. Frontiers of Entrepreneurship Research. Babson College. Disponível em: <http://www.babson.edu/entrep/fer/papers98/I/I_A/ I_A.html>. Acesso em: Novembro/2011.

Hornaday, J. A.; Aboud, J. (1971). Characteristics of successful entrepreneurs. Personnel Psychology, 24, 141-153.

Ibáñez, A.; Farah, O. E.; Corrêa, A. M. J. C. (2004). Incubadora de empresas: uma proposta de estudo. Revista Eletrônica do Mestrado de Administração da UNIMEP, maio a agosto.

Jean, B. (1993). A Forma social da agricultura familiar contemporânea: sobrevivência ou criação da economia moderna. In: Colóquio Internacional Sobre Agricultura Familiar, UNICAMP, out.

Jyoti, J.; Sharma, J.; Kumari, A. (2011). Factors affecting orientation and satisfaction of women entrepresneurs in rural India, Annals of Innovation \& Entrepreneurship, Disponível em: $<$ http://www.innovationandentrepreneurship.net /index.php/aie/article/view/5813/pdf_203>. Acesso em: $15 / 12 / 2011$

Kulawczuk, P. (1998). The development of entrepreneurship in rural areas. In: Kimball, J. D. (Eds.), The Transfer of Power: Decentralization in Central and Eastern Europe (97-109). Budapest, Hungary: The Local Government and Service Form Initiative.

Kühn, D. D. (2003). Desenvolvimento Rural e a Abordagem Das Capacitações: O Microcrédito em Constantina/Rs, dissertação UFRGS.

Lassithiotaki, A. (2011). Rural Women And Entrepreneurship: A Case Study In Heraklion Crete Prefecture, Greece. Journal of Developmental Entrepreneurship, 16(2), 269-284.

Liles, P. R. (1974). New business ventures and the entrepreneur. Homewood, III.:Irwin. 
Análise das Barreiras que Dificultam a Transformação do Agricultor Familiar em Empreendedor Rural no Contexto Brasileiro

Locke, R. (2001). Building Trust. Annual Meetings of the American Political Science, Massachussets Institute of Technology, Mimeo.

Lumpkin, G. T.; Hills, G. E.; Schrader, R. C. (2001). Opportunity recognition: A CEAE White Paper. University of Illinois at Chicago.

Man, T. W. Y.; Lau T. (2000). Entrepreneurial Competencies of SME Owner/Managers in the Hong Kong Services Sector: a Qualitative Analysis. Journal of Enterprising Culture, 8(3), 235-254.

McClelland, D. C. (1971). Entrepreneurship and Achievement Motivation: Approaches to the Science of Socio-economic Development. In: Lengyel, P. (ed.), Paris, UNESCO.

Mitchell, V. W. (1999). Consumer perceived risk: conceptualizations and models, European Journal of Marketing, 33(1-2), 163-195.

Miyazaki, J. ,Vilas Boas Teodoro, P.A. Raizel,T. (2008). Capital social e empreendedorismo rural: a agricultura familiar no oeste do Paraná. Resultados Preliminares do Projeto: Gestão das Unidades Artesanais. Disponível em: http://www.unioeste.br/campi/cascavel/ccsa/IVSem inario/IVSeminario/Artigos/11.pdf >. Acesso em: $10 / 12 / 2011$

Ozgen, E.; Minsky, B. D. (2007). Opportunity recognition in rural entrepreneurship in developing countries.

International Journal of Entrepreneurship: Annual. 11.

OECD (2003b). Entrepreneurship and local economic development - Programme and Policy Recommendations - OECD - Paris.

Palmer, M. (1971). The application of psychological testing to entrepreneurial potential. California Management Review.

Petrin, T.; Gannon, A. (1997). Rural development through entrepreneurship. FAO, Rome (Italy). Regional Office for Europe. Disponível em: $<$ http://agris.fao.org/agris-

search/search/display.do?f=1998/XF/XF98005.xml; XF1998077983>. Acesso em: 15/12/2011.

Pickle, H. B. (1964). Personality and success: Na evaluation of personal characteristics of successful small business managers. Small Business Research. Series n. 4. Washington, D.C.: U.S. Government Printing Office.
Raupp, F.M.,Beuren,I.M. (2009) Programas oferecidos pelas incubadoras brasileiras as empresas incubadas, Revista de Administracao e Inovacao , SP, v.6.n.1, p.83-107,2009

Sampaio Filho, J. A. (2005). Campo, o grande empregador do Brasil. Disponível em: <http://cidadesdobrasil.com.br/cgi-cn>. Jan. edição 57. Acesso em: 15/12/2011

Schneider, C. P. (2008). Agricultura familiar $e$ empreendedorismo: um estudo sobre as trajetórias de jovens egressos do Centro de Desenvolvimento do Jovem Rural (Cedejor) no Vale do Rio Pardo/RS. Dissertação (Mestrado) em Desenvolvimento Rural da UFRGS.

Schumpeter, J. A. (1934). The Theory of Economic Development. Cambridge: Harvard University Press.

Sepúlveda, S.; Rodriguez, A.; Echeverri, R.; Portilla, M. (2003). El enfoque territorial del desarrollo rural. IICA - San José Costa Rica.

Shane, S. (2000). Prior Knowledge and the discovery of Entrepreneurial Opportunities. Organiztion Science, jul/ago 2000. 11(4), 448-469.

E Verkataraman,S. (2000). The Promise of Entrepreneurship as a Filed of Research, Academy Management Review,v.25,p.217-226

Sutton, F. X. (1954). Achievement Norms and the Motivation of Entrepreneurs. In: Entrepreneurs and Economic Growth. Cambridge: Social Science Research Council and Harvard University Research Center in Entrepreneurial History.

Silvestro, M. L., Abramovay,R., Melo M.A., Dorigon,C. (2001) Os impasses sociais da sucessão hereditária na agricultura familiar. NEAD/MDA. Brasília.

Storopoli, J. E. ; Binder, M. P. ; Maccari, E. A. .(2013) Incubadoras de empresas e o desenvolvimento de capacidades em empresas incubadas. Revista de Ciências da Administração (CAD/UFSC), v. 15, p. 36-51.

Timmons, J. A. (1978). Characteristics and role demands of entrepreneurship. American Journal of Small Business, 3(1). 
Análise das Barreiras que Dificultam a Transformação do Agricultor Familiar em Empreendedor Rural no Contexto Brasileiro

Tomei，P.A.,Russo,G.M.,Botino,C.A.(2008), Cultura Empreendedora, Ed.Office Book, Rio de de Janeiro Brasil.

United Nations Industrial Development Organization (UNIDO). (2011) Agribusiness for Africa's Prosperity. Yumkella, K.; Torben, P.; Roepstorff, M.; Hawkins, A. (Editors), fev. 2011. Disponível em: Disponível em: <http://www.unido.org/fileadmin/user_media/Servi ces/Agro-

Industries/Agribusiness_for_Africas_Prosperity_ebook_NEW.pdf $>$. Acesso em: 15/12/2011

Veiga, J. E. (2003). Empreendedorismo Rural - Uma Primeira Aproximação, Relatório para o SEBRAE Nacional, versão setembro.
Welsh, J. A.; White, J. F. (1981) Converging on characteristics of entrepreneurs. In: Vesper, K. H. (Ed.) Frontiers of entrepreneurship research. Wellesley: Babson Center for Entrepreneurial Studies.

Winter, D. G. (1973). The power motive. New York: Free Press.

Yu, T. F. (2001).Entrepreneurial Alertness and Discovery. Review of Austrian Economics. March, 14(1), 47-63.

Zahra, S.; Sapienza, H. J.; Davidsson, P. (2006) Entrepreneurship and Dynamic Capabilities: a review, model and research agenda. Journal of Management Studies, Malden, v. 43, n. 4, p. 917955. 